rine arteries and the umbilical vein, and between the umbilical arteries and the uterine veins; but the idea of such a connection is an upphysiological absurdity. There can be no such communication; it is contrary to the laws of general anatomy.

If the placenta be an assistant circulatory organ, as the theory of Mr. Jackson supposes, just so also is the whole capillary system of our bodies; but the placenta is simply the absolutely necessary and indispensable interposition of capillaries, to aroid a double arterio-venous anastomosis. This arrangement is in perfect harmony with the natural laws of physiology, for the interposition of the capillaries is the necessary course which nature universally adopts when a communication is required between the arte. rial and venous circulations.

Some persons have opined that the materual arterial blood is deposited in cells of the placenta, as a pabulum which is there subjected to some suppositious quasi-glandular action, and then taken up by the capillary radicles of the umbilical vein. If this were the case, according to every natural example, it ought to be taken up by absorbents, properly so called, and not by veins, as every one who understands the arrangement and physiology of the capillaries will readily comprehend; but the microscope shows no cells of the kind. The necessity and the proof of such an arrangement are equally hypothetical; but the notion is altogether disproved by the following fact. So long as the foetus is a part of the mother's system, no excreting organ of its own is required by it; and, for the same reason, the maternal blood must be suficient for its development.

I trust that these facts, and the experiments here alluded to, will be considered to be a sufficient demonstration,-

First, that the spleen is merely the necessary interposition of capillaries between the splenic artery (which is the largest branch of the coliac axis) and the venous portal circulation.

Secondly, that the placenta is simply a double and deciduous body of capillaries, between the uterine arteries and the umbilical vein, and between the umbilical arteries and the uterine veins.

$I$ believe that $I$ am not mistaken in remarking that none of the theories which have hitherto been offered on this subject have made the slightest approximation to the truth, and that the experiments which I have here described point out the true physiology of the spleen now, for the first time.

4, Queen's-place, Kennington, Nov. 4th, 1842.
ON THE

PHYSIOLOGY AND PATHOLOGY

or

THE SALIVA.

By Samuel Wright, M.D. Edin., F.S.A., Physician to the Birmingham General Dispensary, \&c. \&c.

(Continned from p. 877, Vol. ii., 1841-3.)

\section{ALBUMINOUS SALIVA.}

Saliva, in its healthy state, always contains a nolable proportion of free albumen, which readily answers to the reagents em. ployed for its detection. This constituent is liable to vary in quantity, but if below .02 . or above .5 per cent., the secretion cannot be considered normal.

A disordered action of the salivary glands, per se, or a disturbance of their function through a derangement of the system, is often productive of an increase of albumen in the salival thuid. In the former instance the secretion retains its transparency, or as, more frequently happens, is unusually limpid; is the latter it is invariably turbid, and has a dull white appearance.

a. Transparent Albuminous Saliva - - This variety somewhat resembles filtered saliva in its aspect; there are no flocculi on nebula in it, unless they be derived from the lining mernbrane of the mouth; it is almost perfectly transparent, and never, or only in the remotest degree, has a blue tinge. It contains less ptyaline than natural, but its sulphocyanogen is generally increased. It is very tenacious, froths excessively when agitated, and by boiling yields an abundant coagulum. It is strongly alkaline, and of greater specilic gravity than natural. It easily decomposes, becoming at frst turbid, and then mouldy and ammoniacal.

Albuminous saliva digests and changes starch in a degree inferior to the healihy secretion. It produces the same quantity of gum, bnt less sugar and lactic acid. This may perhaps be owing to the excess of alkali in the fluid.

This variety of saliva is secreted only when the salivary glands are in a state of unusual excitement; and this excutement is either spontaneous, and apart from any disturbance or disorder of the system at large, or is produced by the action of some local initants.

The salivary glands rarely, under any cir. crmstances, furnish transparent albuminous saliva for more than six or eight hours; after that period the secretion either degenerates into the opake variety, or recovers its natural character. It is generally more abundant than healthy saliva, but is never discharged profusely.

The secretion of this saliva is commonly preceded by heat, pain, and tumefaction of 
the salivary glands; subsequently, they are in the mouth.* There is generally thirst, affected by a pricking or itching sensation, with often a defective or capricious appetite, which usually subsides after a few hours. headach and languor, or stupidity. The If the inflammation persists longer, it is eyes are red and watery; urine scanty sometimes relieved by a spontaneous ptya- (though $I$ have once or twice found it lism, the secretion losing its transparency, remarkably abundant); bowels confined and and its excess of albumen; at other times the saliva will be diminished, and the local excitement will continue to suppuration.

Revulsives, depletives, and sedative gargarisms, constitute the best treatment when remedies are indicated. But unless the symptoms become aggravated, it is scarcely necessary to interfere, unless to gargarise the mouth with some sedative solution, such as I have already prescribed.

The excitement of the salivary glands upon which the secretion of albuminous salipa depends, is very liable to recurrence. Seldom after the second or third attack is the saliva perfectly transparent; in the subsequent seizures it gradually becomes opake, until at last it degenerates into the "white" variety.

$\beta$. Opake Albuminous Saliva: White Sallira.-This saliva differs in many important respects from the matural secretion. In its extreme form it is perfectly opake, and has a milky appearance. Boiling produces an abundant coagulation, and the albumen swims in flakes through the liquid, subsidiug finally, and leaving a superstratum which resembles whey. Its specific gravity is greatly above the natural standard; the highest I have met with has been 1.0168, and the lowest 1.0095. It is less tenacious than the transparent variety, though considerably more so than bealthy saliva. Ptyaline and sulphocyanogen are generally present in minute quantity, but I have occasionally remarked the absence of the latter. 'This saliva is always strongly alkaline, and has either a mucous or a mouldy smell. It often contains an adventitious fatty or oily matter. It froths remarkably when agitated, and its bubibles are permanent. It absorbs oxyren very sparingly, and exerts but little action upon starch. After a few hours it becomes flocculent, and shortly decomposes, evolving hydrosulphuret of ammonia. I have met with more than one specimen which has aftiorded prussic acid during the process of decay.

'This saliva is never secreted in profuse quantity, and therefore cannot be easily collected for aualysis. I have only been able to examine it sufficiently to determine its amount of albumen, which $I$ find to be very variable. In four specimens it was relatively $.6: 3, .96,1.01$, and 1.03 , per cent.

The secretion of white saliva is always indicative of a disordered and sluggish state of the salivary glands, either the consequence of previous excitement, or symptomatic of imperfect and impaired digestive function. The accompanying signs are a furred tongue, pale or brownish, and an oily or bitter taste

After spontaneous or excited ptyalism the white salıva not uncommonly prevails. In small-pox it is often observable. "Die autem fere undecimo saliva viscidior jam facta, agcrrime excreatur." - Sydenham (Op. Med., Genev. 1736, tom. i., p. 83). I have remarked it in several cases of critical salivation. After the use of mercury I have several times noticed it, but especially after the use of jodine. Indeed, 1 have often known the latter medicine to diminish and whiten the saliva without having previously augmented it. In one case, in particular, the patient had taken half a drachm of hydriodate of potass daily, for a fortnight, with perceptible benefit. The appetite was good and the secretions natural. One evening, however, a violent diuresis supervened, and continued unabatedly for several days. During this period, and for some time subsequently, the salivary fluid was much diminished, and as white as milk. The digestion also became impaired, and it was not until after a steady and persevering use of tonics and stimulant gargarisms that the function of the salivary glands and of the stomach was restored to health and activity. In this instance the inordinate discharge by the kidneys appears to have been the chief cause of the diminished salivary secretion. Nor is it unfrequently consequent upon the use of stron diuretics. I have also observed the same effect, though in a milder degree, to follow the spontaneous increase of the renal secretion. Hence one reason of the prevalence of white saliva in diabetes. "Saliva alba spumosa." (Commentarius Wenceslai Trnka. De Diabete, 1778, p. 16.) Dr. Good has particularly remarked a "frequent excretion of very white saliva, not inspissated, but yet scarcely fluid." (Study of Med.v. 5, 47i.) At the commencement of inflammation of the lungs the saliva is generally white. I have also remarked it in abdominal dropsy, and often in constipation. But it is most frequently met with in disorder of the stomach accompanied with local nervous debility, or with vascular congestion. It is especially common in the glutton and the drunkard. +

* The salivary glands and lining membrane of the mouth have often a congested and livid appearance.

+ Falstaff says,

" ‘_ If it be a hot day and I brandish anything but my bottle, I would I might never spit white again.'-2 Henry IV., 1, 2. "His meaning is, May $I$ never again have wine enough to produce that effect; or, 
The secretion of white saliva is sometimes though somewhat thinner. This flux of only temporary, and requires us to do green and bilious saliva continued for about nothing more than to gargarise the mouth forty hours, during which time the quantity with cold water, or with some moderately discharged amounted to four pints. The stimulating liquid. At other times it will colour of the saliva then changed to yellow, persist, much to the annoyance of the like a solution of gamboge, with an increase patient and to the disturbance of his rather than a diminution of the quantity. digestion. Under these circumstances it is it continued of this colour for the space of requisite to employ stronger gargarisms, and forty hours more, after which it gradually to aid their action by local blistering. Fre- became pellucid, and the salivation ceased quently the disorder of the stomach and as suddenly as it came on. During the llow torpidity of the bowels indicate the necessity of the saliva the feeth and fauces were as for mild tonics and aperients. These, how- green as if they had been stained with ever, will not be called for if the saliva be restored to a healthy state and quantity.

\section{BILIOUS SALIVA.}

A yellowness of saliva, from the presence of bile, has often been remarked by medical writers. "Subinde etiam colorem (saliva) deponit, et ex albo, fit crocea." Nuck (Sialographia). Riedlinus observes, "Adeo haud raro icterum omne, quod in corpore humano reperitur, serum flavo colore tingere, ut non solum tota cutis codem infecta conspiciatur, sed et talis e naribus nucus emungatur ipsaque in ore saliva tincta rejiciatur. (Linear. Medic., An. 1697, Feb., Obs. 7, p. 88). It is mentioned by Donatus (Hist. Med. Mirac. lib. 1, c. 9, p. 74); Petermannus (Disp. de Icter. ex Calcul. Vesic. Fell. Lips., 1696, cap. 2, s. 6) ; and Valcarenghus (Medic. Ration. p. 241). One of the most remarkable cases on record is that related by Dr. Huxham in the "Philosophical Transactions" for 1724, vol. 33:"The patient was a man aged forty, of a spare, bilious habit, who had an attack of jaundice, followed by a paroxysm of colic, this last being produced by drinking too freely of cyder. Amono other medicines was given a bolus, containing a scruple of jalap, eight grains of calomel, and a grain of opium. Copious dejections followed, and a fow hours afterwards the patient complained of pain and swelling in the fauces, aud spat up a little thick, brown saliva, which was soon considerably increased in quantity, of a dcep colour, resembling greenish bile,

rather, perhaps, may $I$ never have a debauch over night to make me thirsty in the morning.

"Spungius says, in Massinger,

" ' $ـ$ Had I been a pagan still, I shonld not have spit white for want of drink.' - Virg. Mart. iii. 3.

"That is, for want of more drink to remedy the effect of what he had taken before. It was noticed also as a consequence of habitual intemperance. The unlucky pages in Lyly's Mother Bombie say that their masters had sodden their livers in sack for forty years, and

" "That makes them spit white broath as they do." -Act iii. scene 1.

See Nare's Glossary. verdigris, aud the teeth relained the same colour for a fortnight after the ptyalism had ceased. The patient had, a few years before, been suddenly attacked by a spontaneous salivation, so excessive as to endanger his life." (See Good's Study of Medicinc, vol. i., p. 76.$)$

Bilious saliva chiefy occurs in two forms, coloured and colourless; more marely it is met with containing only cholesterine.

Coloured bilious saliva is of various shades, from a golden yellow to a deep olive. The lighter specimens are generally alkaline, the darker are not uncommonly acid. The specific gravity of this saliva is greater than natural; its smell is sickly and offensive; its taste bitter and nanseous; it froths easily when agitated, and coagulates abundantly by boiling; proiracted ebullition renders it ammoniacal and deepens its hue; it contains only a minute trace of ptyaline, which usually has the colour of the original Huid ; sulphocyanogen is generally wanting; it exerts scarcely any action upon starch; it readily becomes putrescent, and then evolves either ammonia or its hydrosulphuret.

A specimen which I once examined afforded the following constituents:--

Water .................980.7

Ptyaline ............... .5

Fatty matter and fatty acid .... 1.3

Biliary matter.............

Cholesterine ............ .4

Albumen, with soda and albu-

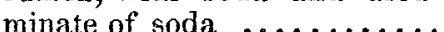

Mucus ............... 1.6

Carbonates

Nuriates

Phosphates

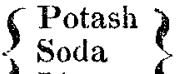
$\ldots \ldots$

Loss..................

1000.0

In analysing this variety of saliva it is advisable, after having removed the ptyaline and fat by ether, to pass boiling alcohol through the filter until everything solubic in that menstruum has been removed. By carefully evaporating and crystallisine, the

* The term, colourless, I employ only relatively, to distinguish the species of saliva which it represents from the opposite, which strongly contrasts with it in a bilious tinge. 
cholesterine may be separated; and by digesting absolute alcohol upon the residue the biliary matter will be extracted and the chlorides left. The remainder of the analysis may be conducted in the usual manner.

Colourless bilious saliva, as its designation is intended to signify, is free from any appearance of intermixture with biliary matter. Still it is never so transparent as the natural secretion, and has either a dead white or a slightly dingy aspect. It is sometimes bitter, but more frequently imparts a mouldy taste to the tongue. It is always alkaline, with an abundance both of albumen and mucus. Its sulphocyanogen is deficient, though rarely wanting; ptyaline is present in rather less proportion than natural, and its odour is not recognisable in the saliva, whether cold or hot. The addition of nitric or muriatic acid produces, after a few minutes or a few hours, a dull yellow colour, which gradually deepens to a faint olive. Protracted boiling, and spontaneous decomposition, give rise to the same effect in an inferior degree.

This saliva will convert a small quantity of starch into gum, but it never generates any sugar.

That saliva should contain bile without its presence being indicated by its colour, is a curious fact, though by no means an uncommon one; for my own ooservations have led me to the conclusion that the latter variety of saliva is much oftener to be met with than the former. It is not easy to account satisfactorily for the difference, but perhaps the theory will not be far from the truth if we suggest that in one example the bile is simply intermixed with the saliva, and in the other is in intimate combination with it.

Saliva which contains cholesterine, free from intermixture with bilıary matter, is of rare occurrence. I have seen it only twice-in one instance accompanying dyspepsia with hepatic derangement, and in the other succeedug to an attack of jaundice. In the former case it lasted for three or four days; in the latter, for about a day and a haif. The quantity secreted was scarcely more than ordinary, but my attention was directed to it from the patients complaining of a greasy taste in the mouth.

This saliva is white and shining, and more dense than ordinary; it has an alkaline reaction, does not redden a persalt of iron, and is nearly odourless. Its albumen is in excess, but its saline constituents are in small proportion; it possesses feeble digestive properties, and is slow of decomposition.

A discharge of bilious saliva, whether coloured or colourless, either accompanies, precedes, or prevents, an attack of jaundice. 'The former variety usually attends the jaun. diced state, the latter more commonly foreruns it. The one, consequently, either removes or mitigates, the other either averts or restrains the disease.
As before remarked, coloured bilious saliva is much the less common of the two. It is generally vicarious of an imperfect action of the kidneys, bowels, or skin; its quantity is always abundant, and though it sometimes alteruates with that of the other secretions, it rarely permanently diminishes until the patient is free from the jaundiced tinge. The salivary glands are usuilly tinged, and of a dull red colour, but they are not painful, and they present no signs of active iniammation.

CASE 1.-Mary S., ætat. 28, a washerwoman, was under my care in Edinburgh, in 1839 , for an attrock of idiopathic jaundice. During the space of a week she was treated with alkalies, salines, mercurials in altera. tive doses, and aperients, but with little or no benefit. The yellowness of the skin continued, the urine was londed with bilc, and the freces were like pipe-clay. On the morning of the eighth day she complained of stiffness and aching of her jaws, and of heat in the neighbourhood of the parotid and sub. maxillary glands, which were considerably swollen. In the afternoon the salivary secretion was much augmented, and it was stated to be excessively bitter. After having swallowed it for some time, she became narseated, and at last vomited severely. Subsequently the ptyalism increased, and she spat for three or four days two quarts daily of saliva, deeply tinged with bile. It was intensely bitter, and always excited nansea or vomiting if swallowed. During the continuance of the salivation the fæeces remained clay-coloured, and the urine became more clear, yet the conjunctiva and skin gradually lost their yellowness, and the patient's health was considerably improved. On the thirteenth day the saliva recovered its usual colour, and was scarcely more ahundant than common; at this time an active dialrhoea supervened, and the fixces were again natural. On the cessation of the purging the patient was convalescent.

Case 2.-Thomas H., ætat. 36 , a gardener, living in a small village in the county of Nottiugham, consulted me in March, 1841, for an attack of jaundice under which be had been suffering for nearly three weels. I treated him for several days upon a tonicaperient and alterative plan, comprising chiefly rhubarb, taraxacum, mercurials, and preparations of iodıne, but without benefit. In the afternoon of the sixth day he complained of a bitter taste in his mouth, with aching of the jaws, and a sense of weight in the pharynx. His mouth was unusually moist, and he was incessantly gaping. In the evening of this day he became the subject of profuse ptyalism; the saliva was of a dull yellow colour, and intensely bitter. There was no mercurial foetor of the breath, the gums were not spongy, nor was the mem. brane of the mouth abraded. From the date 
of the salivation his health began to improve, / saliva contained no bile. In eighteen hours, and the tinge of his skin sensibly declined. however, it became thorougbly bilious, and The discharge persisted for three days (dur- the patient again began to improve. The ing which time the urinary and facal evacuations were scanty and depraved), when suddenly the salivary glands became almost inactive, and in a few hours the patient was as yellow as ever. I was unable to see him until the following day, at which time a vio. lent diarrhoea had supervened and was freely unloading the system of its accumulated bile. The patient's strength enabled him to bear this evacuation, which was consequently not interfered with. It continued, gradually decreasing, for a few days, and finally left its subject free from ailment. The saliva was not afterwards bilious, and was secreted in natural quantity.

CASE 3.-Susan T., ætat. 25, was under my care in August, 1841 , for an attack of jaundice. At the time I first saw her she had been ill for three days; her skin was deeply yellow; urine scanty and very dark; bowels costive; faces clay-coloured. She was treated with salines and aperients for nearly a week, but with little manifest im. provement. She constantly suffered from a bitter taste in her mouth, and her salivary secretion was rather augmented. On the fourth day these symptoms were more marked, and they gradually increased until the ninth day, when an active ptyalism com. menced. The saliva, of which she spat nearly a quart daily, was deeply bilious, nauseous, and bitter. After the occurrence of the salivation she complained less of general uneasi. ness, and her complexion greatly improved, although the renal and intestmal evacuations continued unchanged. The salivary discharge was constant for nearly five days, at the end of which time the yellowness of the skin was barely perceptible, and the patient's health was much better. Unfortunately, in walking to a friend's house she was drenched in a shower, and omitted afterwards to change her clothes. She complained in the evening of chilliness, and especially of cold and numbness of her feet. I saw her the next morning, when she was suffering from pyrexia, with a complete cessation of the ptyalism. In the afternoon of this day her jaundiced aspect had entirely returned. I ordered renesection, with salines, antimonials, and mercurials. On the following day the febrile symptoms were much abated, but the shin was becoming darker; the urine was scanty, turbid, and foul; freces loaded with mucus, but totally wanting in bile. The salivary secretion was still very sparing, but the patient did not complain of a bitter taste. The antiphlogistic treatment was ordered to be continued, and, additionally, the capsicum gargarism was directed to be used every three hours. After a few trials the salivary glands became more active, and the ptyalism was in a short time restored, but the gargarism was used during the next four days, to the effectual relief of the system. The bowels were also stimulated by suitable aperients, and subsequently the bile was discharged by its accustomed channel. The saliva, on the arrest of the stimulation, became natural, and the patient was speedily restored to health and energy.

As we have before said, in treating of the physiology of saliva, this fluid is to be regarded as a pure secretion, provided for the purpose of variously aiding the digestive function. Its increased discharge is injurious to the system only from the debility which it induces, and its presence in the stomach in undue quantity is hurtful merely from the local irritation which it excites. This is a simple estimate of its ordinary and extraordinary physiological servitude. In a pathological sense, however, it is capable of becoming disordered, per se, to an extent sufficient to render it not only useless, but pernicious to the stomarh; it may then be fairly regarded as an excretion; and, again, it may be healthy in the number and proportion of its constituents, but depraved from the presence of some foreign material which is being removed from the system by the salivary channel. In the former case the salival glands are the active, in the latter, the passive, adulterators of their secretion.

In diseases which, like jaundice, involve a corruption of the blood from retention or resorption of effete matter, this is generally eliminated by some of the emunctories-the kidneys, bowels, or skin. In this manner the system is lightened of its burthen by vicarious actions which are comparatively harmless. Sometimes, however, the excretory organs intermit or suspend their vicarious function, and the bluod becomes oppressed and its action paralysed by the accumulated morbific matter, and death is the speedy consequence. Under other circum. stances, as we have seen in the cases just recorded, the office of an excernent organ becomes delegated to a secernent one, and the system is relieved at the expense of a secretion whose services are requisite for healthy digestion and assimilation. If this action were persistent instead of temporary, gradual wasting and death would follow; but when limited in its duration, it is one of those expediencies of nature which can be borne with impunity; and though, as in the cases under our notice, the stomach may be disordered through a want of its accustomed proportion of healthy saliva, and the constitution may be debilitated from imperfect nutrition, these are evils which admit of an ultimate remedy, and bear on comparison with that train of mischief which follows a continued corruption of the vital fluid. Hence, when the blood is loaded with bile, perhaps rapidly accumu- 
lating, and it fails to be discharged by the kidneys, bowels, or skin, we may regard it as a very fortunate event if the morbific matter obtain an exit by the salivary glands, until its elimination can be secured by other and more appropriate organs.

In cases of bilious salivation, we should especially guard against any sudden check to the discharge, which ought rather to be encouraged, whilst, at the same time, we use persevering but gentle means to invite the excretory apparatus to its accustomed duty. Neither powerful diuretics nor purgatives should be employed, but the kidneys and bowels should be gently stimulated by salines and aperients, with an occasional mercurial, and the skin should be excited by friction and the use of the warm bath. By these means, and by a careful precaution against cold, a healthy function will probably soon be restored, and most likely it will be permanent. If, however, we imitate the kidneys by violent diuretics, or the bowels by active cathartics, we shall incur the risk of suspending the critical salivation, and, perhaps, at the same time, fail to relieve the system by the other evacuations. I have seen a brisk purgative check the secretion of bilious saliva without obtaining a discharge of bile through the intestines. Should a casual diarrhoea or diuresis, not bilıous, supervene npon the ptyalism, it must be moderately suppressed by astringents, sedatives, and the warm bath; but if the diarrhcea or diuresis be critical, and suficiently bilious, it may be either let alone, or indirectly assisted by whatever means are calculated to promote it.

If the ptyalism should cease spontaneously, as is sometimes the case, the emunctories still failing to carry off the accumulated bile, we must use every chort to restore the activity of the salivary glands. The mouth is to be frargarised with stimulant solutions, aided by the steam of hot water, or chlorine water, and, if necessary, local blistering should be employed. These means will be found much more efficacious than mercury, which occasionally fails to restore a critical salivation under such circumstances; and cven when successful its effects are gencrally slow, and often an impediment to perfect recovery.

Colourless bilious saliva occurs, for the most part, in those cachectic states of the system which, in adults, are the consequence of irregularity and excess; and which, in elderly people, are connected with a change of life, or with a breaking-up of the constitution. In such cases, the function of the liver is imperfectly performed,-sometimes owing to a sluggishness of the organ, but oftencr to a permanent change of its structure. Not only the quantity but the quality of the bile is unnatural; it tinges the system, and taints most of its secretions. It imparts various shades of red, yellow, and green, to the urine, fæces, and sweat, but its presence is scarcely indicated inthe saliva, excepting by the addition of an acid, by long boiling, or by decomposition. This appears to be owing to some modification which the bile undergoes in its passage through the salivary glands. In the present example, the bile does not, as in the previous variety, simply escape with the saliva; but being small in quantity, and slow in its separation from the blood, it becomes to a certain extent subject to the laws which contribute to the formation and preservation of the salival fluid; and even after the secretion of the saliva, and its discharge from the mouth, the forces, chemical, physical, and vital, with which it was endowed in the process of its generation, continue to act until the proportion and harmony of its constituents have been destroyed, either by spontaneous decomposition or by artificial agency. There is, perhaps, not any animal secretion more uniform and complete in its nature and composition than healthy saliva. In the nice ratio of its constituents, and in its properties, physical, chemical, and physiological, we have an evidence that the secernent function which produces it is one of the most perfect processes in the economy of life. The balance having been broken, one constituent having become independent of another, and subject to laws purely che. mical, restraint is no longer exercised upon any adventitious matter, and, of conrse, its presence and power become immediately ap. parent.

Colourless bilious saliva is never secreted in excess; directly that its quantity amounts to salivation, it merges into the coloured variety. The proportion of bile is then increased, and the distinctive characters of saliva are lost. This variety of the salivary fluid often exists for a long time withont affecting the patient further than by imparting a yellowness to his teeth and tongue, and a sense of bittelness or mouldiness to his taste. In some people it colours the teeth permanently yellow, green, brown, or black, according to the amount of bile present, and its facility of decomposition. In others it discolours the tartar of the teeth $j_{n}$ the same manner. It is rather negatively than posi. tively injurious to digestion. As before said, it will convert starch into gum, but not into sngar. It is usually accompanied with symptoms of dyspepsia; a furred yellow tongue, red at the tip and underneath; congestion of the lining nembrane of the mouth; pain in the stomach after eating; acid eructations, and sometimes romiting of yellowish or greenish matter; pain in the right side and under the right shoulder; headach or dizziness; dimness of vision and singing in the ears; constipation; variableness of temper and appetite, \&c.

With some people this condition of the saliva will persist for weeks and months with little variation; in other's it will vary 
according to the state of the excretions; if purging, diuresis, or diaphoresis occur, and the matter discharged be abundant in bile, the saliva may become healthy in a few hours, and, perhaps, continue so; but it often degenerates again after a day or two. Still, it rarely happens that an increased discharge by any of the emunctories supervenes without the saliva being temporarily or permanently restored to a natural state. In old cachectic people it is often very continuous or recurrent; in adults it is generally consequent upon excesses, may subside spontaneously, is easily remedied, and not liable to a return, except through the means which originally produced it.

Whenever colourless bilious saliva is secreted a disturbance in the action of the liver and a disorder of the system may always be suspected. A continuance of the secretion often prevents jaundice, and frees the system from the incumbrance of bile, until its functions have again recovered their healthy tone and balance. However, in spite of the diecharge of hile by the saliva, jaundice will occasionally follow, sometimes running a protracted or a fatal course, and at others being cut short by a critical discharge of coloured bilious saliva, or by active diuresis or purging.

The existence of colourless bilious saliva is determined by the symptoms which $I$ have already detailed, and by a discolouration of the secretion on the addition of nitric or muriatic acid. The treatment should consist in the exhibition of such remedies as are calculated to restore a healthy activity to the liver, stomach, kidneys, and skin. If practicable, the patient ought to have horse exercise daily, and take a hot bath twice a week, using the flesh-brush vigorously after each immersion. Gentle mercurials with aloetic purgatives should be administered every night; and tonics of calumba, quassia, rhu barb, or taraxacum, with alkalies, twice or thrice a-day. After having corrected the state of the stomach, and obtained a good action by the kidneys and bowels, the salivary glauds shou?d be gently excited by a stimulant gargarism, to remore their congestion and torpidity, and so to restore to them a more energetic and healthy function.

\section{(To be continued.)}

Baglivi used to employ a singular metaphor to convey his notions of the ris medicatrix naturø. Hie likened the animal frame in disease to a man having fallen into a well, to aid whom everything that comes to hand is thrown in ; and after a multitude of useless matters he often chances to find some one of these serviceable in helping him to get out. Nature acts in a similar manner against diseases, being ready to derive benefit from the first remedy the eflects of which tend toward recovery.
ILLUSTRATIONS OF

\section{CARDIAC DISEASE,}

DESIGNED TO SHOW THE

\section{PHYSICAL SIGNS AND POST. MORTEM APPEARANCES}

OF THAT CLASS OF MALADIES; AND THE CONNECTION EXISTING BETWEEN THE MORBID CONDITIONS OF THE HEART ANE OTHER ORGANS AND TISSUES OF THE BODY.

By R. H. Semple, Esq., Surgeon, Islington.

\section{I.-Disease of the Aortic Valves.}

Mary Ann Lawson, ætat. 35, has been married eleven years, and has had five children; she menstruated six weeks before the present report. On the 5th of November, 1811 she had a fright, from meeting a drove of bullocks, which circumstance caused a miscarriage the same day, the foetus being in the fifth month of gestation. Before this occurrence she had never suffered a day's illvess, excepting in her confinements, from all of which she recovered rapidly. But a week after the abortion she was attacked with pains in her limbs, especially in the left arm and hand. She took medicines and applied blisters, but was not bled. Under this treatment the pains in the limbs were relieved, but she was then seized with palpitations of the heart, which have continued ever since, together with violent pain, which comes on suddenly, and lasts from an hour to an hour and a half. She went into St. Bartholomew's Hospital, under the care of Dr. Roupell, but did not derive much benefit from the medicines prescribed. She was at last admitted into the Islington Infirmary, on the $30 \mathrm{th}$ of March, 1842, presenting the following symp. toms :-She is pale and exsanguine, and her lips are of a bluish colour ; she is very thin, and her face presents an appearance of great anxiety. She sits up in bed, not being able to lie down with comfort; and in respiration the muscles of the neck are in constaut and rather violent action. Her sleep is much disturbed, and she is often awakened by violent attacks of dyspnoea and spasm. Appetite bad; not much thirst; bowels generally confined; tongue clean; passes her water freely, and in the usual quantity; the urine is generally turbid. Never had swelling in the legs, nor did she ever spit blood. Pulse feeble, but regular.

Auscultation.-Sounds of the heart heard over a much greater extent than is natural, being heard distinctly over the right nipple; but the impulse is not at all increased. There is a loud murmur, of a sharp sawing character, heard with both sounds of the heart. These murmurs are heard at the apex of the heart, but become much more loud, in proceeding with the stethoscope upwards, towards the base; they are also distinctly heard in both carotids. There is no swelling 